\title{
O Significado Medida dos Números Fracionários: aprendizagens na forma de conhecimentos em ação
}

\author{
Activities with Meaning Measure of Fractional Numbers: learning in the form of \\ knowledge in action
}

\author{
Valéria Espíndola Lessa \\ lessavaleria@gmail.com
}

\begin{abstract}
Resumo
Este artigo apresenta uma discussão a respeito da compreensão do conceito de número fracionário, a partir de seu significado medida, utilizando a Teoria dos Campos Conceituais, desenvolvida por Gerard Vergnaud, como referencial teórico. Com base em algumas atividades propostas a alunos do $6^{\circ}$ ano do Ensino Fundamental e nas análises das respostas e atitudes deles frente a estas atividades, identificamos as aprendizagens na forma de conceitos em ação e teoremas em ação (conhecimentos em ação).
\end{abstract}

Palavras-chave: Números Fracionários. Significado Medida. Ensino-Aprendizagem.

\begin{abstract}
This paper presents a discussion of understanding the concept of fractional number from its measure meaning, using the Conceptual Fields Theory, developed by Gerard Vergnaud, as a theoretical framework. Based on some of the activities proposed to students in the 6th grade of elementary school and analyzes the responses and attitudes of them against these activities, we have identified the learning in the form of concepts in action and theorems in action (knowledge in action ).
\end{abstract}

Key-words: Fractional Numbers. Meaning Measure. Teaching and Learning

Muito se tem escrito sobre o ensino e a aprendizagem de números fracionários em nosso país, mas os problemas na escola continuam a ocorrer: professores tentam ensinar mas muitos alunos não conseguem aprender. E consequentemente os alunos que não aprendem este conteúdo escolar criam resistência aos cálculos envolvendo números racionais na sua representação fracionária, optando, na maioria das vezes, em efetuar as transformações para números decimais.

A fuga para os números decimais pode resolver grande parte dos problemas dos alunos, mas é importante investigar e criar estratégias didáticas de modo a modificar este quadro. Os números fracionários são úteis na sociedade moderna e não devem ser ignorados na escola. Neste artigo discutiremos o ensino e a aprendizagem dos números fracionários não na dimensão prática dos algoritmos, mas na sua compreensão conceitual. 
Para discutir o conceito de número fracionário somos levados a reconhecer as diferentes interpretações que uma mesma fração pode ter se associada a situações diferentes. Poderíamos tentar responder a pergunta “o que significa 2/3?" e encontraríamos várias indagações: seriam dois pedaços de um bolo que está partido em três pedaços iguais? Seria dividir igualmente duas pizzas para três pessoas? Seria fazer um suco, onde para cada duas medidas de suco concentrado temos três medidas de água? Seria $\mathrm{R} \$ 6,00$ de $\mathrm{R} \$ 9,00$ ? Ou ainda, seria um número associado a um ponto da reta numérica e, portanto uma medida?

Segundo Kieren (apud Rodrigues, 2009) a construção do conceito de número fracionário deve levar em consideração diferentes interpretações e significados, e propõe quatro "subconstructos": quociente, operador, medida e razão, na qual o parte-todo Kieren considera como estando presente nas demais situações. Acreditamos que a aprendizagem do conceito de número fracionário se dá mediante o desenvolvimento de todas estas interpretações, de forma integrada, ao longo da vida escolar dos alunos.

No entanto, o ensino de número fracionário na escola básica, em geral, se dá apenas pela definição de fração, cujo trabalho é baseado no significado "parte-todo", a partir da partição de um todo, representado por figuras na forma de chocolates, bolos e pizzas, conjuntos de elementos, seguido do estudo de operações de forma mecânica. Não é objetivo deste artigo fazer uma discussão a respeito dos diferentes significados dos números fracionários ${ }^{1}$, portanto focaremos o estudo do significado medida.

Nesta interpretação, o número fracionário na forma $\frac{a}{b}$, com a e b inteiros positivos e b nãonulo, é associado a ponto sobre a reta numérica e o seu caráter quantificador indica a medida do segmento com extremidades neste ponto e naquele que é identificado com o número zero (a origem da reta).

Nossa escolha em discutir este significado em especial se justifica pelo seu caráter contextualizado e natural com que se apresenta em situações didáticas. Segundo Crump (apud Backendorf, 2010), a necessidade de medir comprimento de segmentos (uma quantidade contínua) é um incentivo para o desenvolvimento dos números fracionários - a medida pode ser considerada um meio pelo qual duas grandezas de mesma espécie podem ser comparadas em termos numéricos.

\footnotetext{
${ }^{1}$ Para saber mais sobre os diferentes significados dos números fracionários ver Lessa (2011).
} 
Ao se medir o comprimento de determinado objeto utilizando uma unidade de medida específica - por exemplo, um pedaço de cordão - pode-se encontrar uma relação com a unidade que não corresponde a número inteiro, fazendo-se necessário subdividir o cordão em partes iguais para, então, identificar o número conveniente de partes que são necessárias para ajustar a medida procurada.

A introdução da reta numérica com os números racionais não-negativos pode ajudar na (futura) compreensão a respeito dos números irracionais, e, consequentemente, da reta real, no sentido de superar uma primeira idéia intuitiva (equivocada) de que, uma vez escolhida livremente uma unidade de comprimento, a medida do comprimento de qualquer segmento de reta poderia ser expressa como um múltiplo fracionário adequado da medida da unidade de comprimento adotada.

A figura a seguir apresenta um exemplo utilizando este significado. Observe que a necessidade de medições leva à necessidade do uso dos números racionais, e neste caso o uso da fração parece-nos mais intuitiva do que uma tentativa de aproximação decimal.

Figura 1: Atividade sobre medida

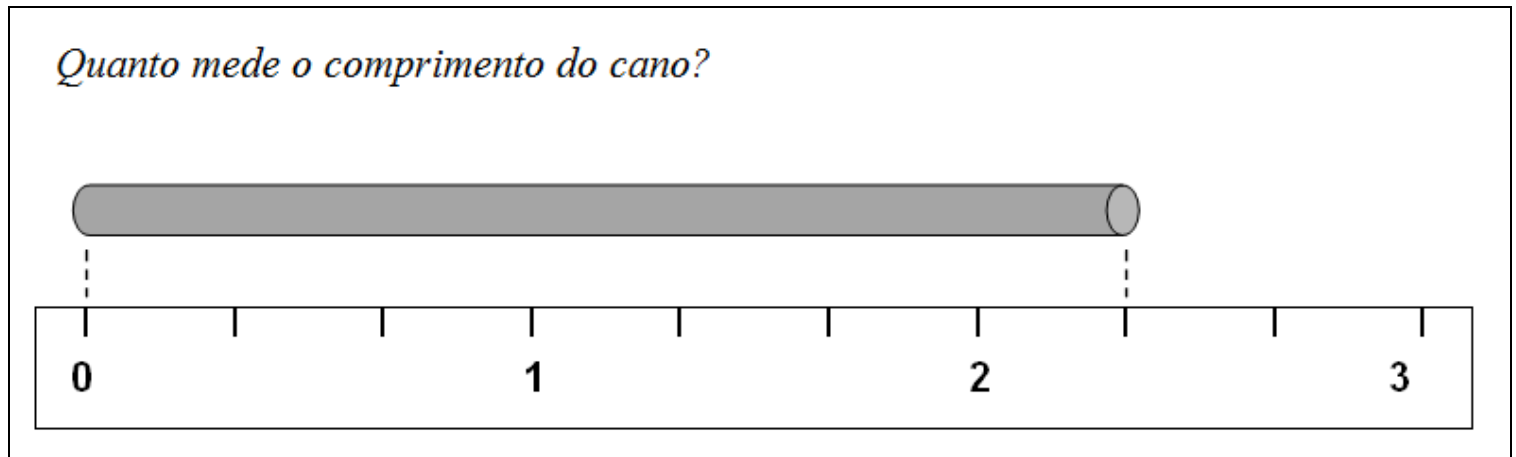

Para entendermos como se dá o processo de construção do conceito de número fracionário, não poderíamos deixar de discutir sobre a construção do conceito em si, e dessa forma, a Teoria dos Campos Conceituais (TCC), criada por Gerard Vergnaud, se apresenta como um interessante referencial. Apresentaremos uma síntese dos principais elementos desta teoria a fim de proporcionar ao leitor um entendimento a respeito do nosso "olhar" quando analisamos as ações dos alunos frente às situações didáticas.

No processo de aprendizagem em que o conhecimento é interpretado como um "campo conceitual", a rede de conceitos que constituem este campo é grande. Quanto ao 
conhecimento relativo a número fracionário, consideramos que este se constitui em um campo conceitual que se insere como um dos componentes de um campo maior - o campo conceitual das estruturas multiplicativas, já bem discutido por Vergnaud em suas obras. Dessa forma, inserimos o conhecimento "números fracionários" como um dos nós com muitas conexões dentro da grande rede de conexões que se constitui no "campo conceitual multiplicativo". A figura 2 traz uma representação sobre como vemos estas conexões da rede.

Figura 2: Esquema de um Campo Conceitual

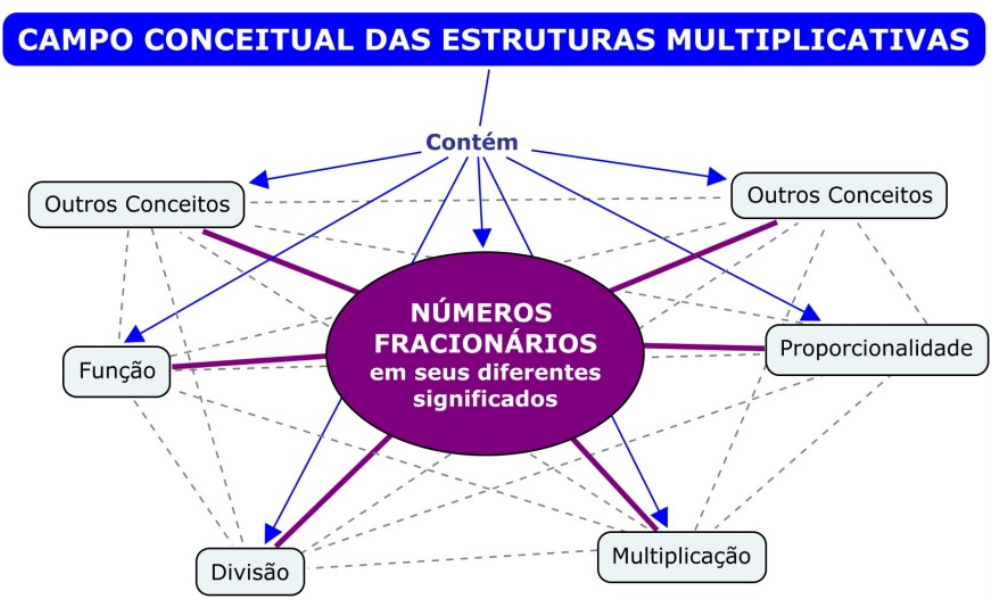

Cabe ressaltar que estes conceitos colocados na figura (função, proporcionalidade, multiplicação e divisão) não são exclusivos de um único campo conceitual, portanto muitas outras ligações podem ser estabelecidas com outros Campos Conceituais. Segundo Vergnaud (2003, p.30), “[...] campo conceitual é um conjunto vasto, porém organizado, a partir de um conjunto de situações". Ou seja, é um conjunto de problemas, situações, conceitos, relações, estruturas, conteúdos e operações de pensamento conectados uns aos outros.

Estabelecido que um campo conceitual é uma rede de conceitos em conexão, avançamos com o entendimento que deve ser atribuído à palavra "conceito" na TCC. Segundo Vergnaud (1996b), um conceito é formado por um trio $\mathbf{C}=(\mathbf{S}, \mathbf{I}, \mathbf{R})$, na qual:

- S: conjunto das situações que dão sentido ao conceito (a referência);

- I: conjunto das invariantes nas quais assenta a operacionalidade dos esquemas (o significado); 
- $\quad R$ : conjunto das formas pertencentes e não pertencentes à linguagem que permitem representar simbolicamente o conceito, as suas propriedades, as situações e os procedimentos de tratamento (o significante).

A partir desta definição de conceito, dada por Vergnaud, apresentamos um diagrama na figura 3 que ilustra como o conceito de "número fracionário" pode ser entendido à luz da TCC:

Figura 3: Esquema sobre o conceito de Número Fracionário

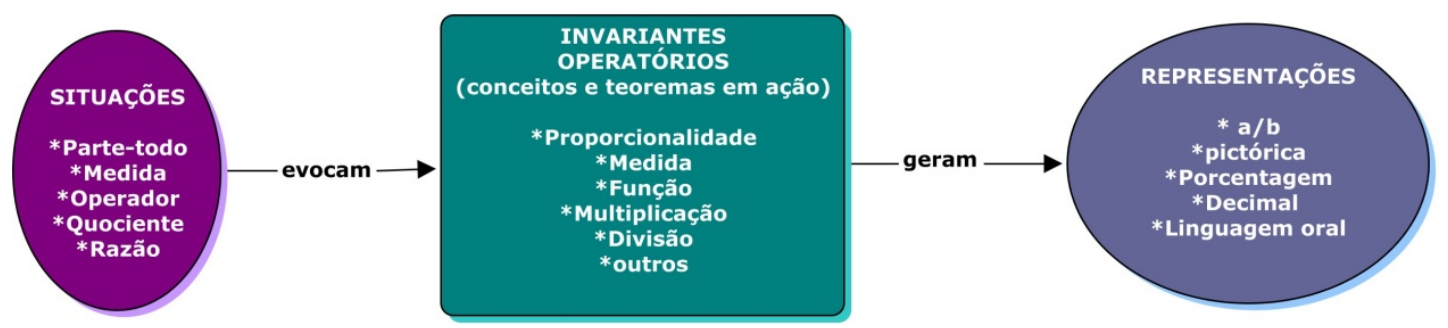

Dessa forma, entendemos que um conjunto de situações e de problemas propostos aos alunos, teóricos ou práticos, envolvendo os diferentes significados do número fracionário - partetodo; quociente; medida; operador; e razão - podem contribuir para que este conceito adquira sentido para o aluno.

Dadas as situações, os alunos utilizarão suas competências para resolvê-las. Nesta busca por estratégias de resolução, os alunos evocam conhecimentos anteriormente formados, fazendo uma "organização da sua conduta". À forma de agir perante as situações e às escolhas dos conhecimentos usados, Vergnaud define como "esquema". Assim, dentro destes "esquemas" podemos identificar os conhecimentos em ação dos alunos frente às situações. Estes conhecimentos, Vergnaud (2009) define como conceitos em ação "um conceito considerado pertinente" e teoremas em ação "uma proposição tida como verdadeira na ação em situação" (p.23).

Em geral, os alunos apresentam dificuldades para expressar os conhecimentos (conceitos e teoremas em ação) utilizados na resolução de um problema e, com isso, a maioria destes conceitos e teoremas permanece implícita. Estando implícitos, estes conhecimentos não são cientificamente aceitos, ou seja, se o aluno não consegue representar na linguagem matemática correta seus conceitos e teoremas, não é possível identificar sua aprendizagem. Para torná-los explícitos, entra em cena o papel do ensino: ajudar o aluno a explicitar, em 
forma de linguagem e símbolos, seus conhecimentos que estão inicialmente implícitos (MOREIRA, 2002).

A identificação dos invariantes é obtida através das representações, mas não só através delas. As representações simbólicas podem ajudar na resolução de problemas quando há dados numerosos e a resposta exige várias etapas; e também ajudam para identificar com mais clareza os objetos matemáticos que são decisivos para a conceitualização. Se o aluno não conhece os termos e linguagem específicos da matemática, reconhecidos socialmente como corretos, para a conceitualização, seus progressos na construção de conhecimento podem ficar comprometidos. Isto porque ele irá criar sua própria representação, repleta de significado e que, não estando "corretamente" escrita, pode ser fonte de dificuldades na comunicação.

Assim, a atenção do professor pesquisador deve estar sobre as representações e sobre as ações. Segundo Vergnaud (2009), "sem a linguagem e os simbolismos desenvolvidos pela cultura, seria impossível identificar estas construções conceituais” (p.29).

Concordamos com Muniz (2009) quando ele escreve que a Teoria dos Campos Conceituais vem contribuir "para a construção de um novo olhar do professor para as produções matemáticas dos alunos" (p.38). E é com este novo olhar que nos colocamos na posição de observadoras do processo de construção do significado de número fracionário, quando tomado como um número que expressa uma medida e que pode ser associado a pontos de uma reta.

Vamos agora apresentar algumas atividades realizadas com alunos do $6^{\circ}$ ano do Ensino Fundamental, envolvendo números fracionários com significado medida, na qual identificamos conceitos em ação e teoremas em ação. São tarefas simples e fáceis de se realizar, o diferencial está no olhar do professor quando observa e faz interpretações.

Na primeira atividade, os alunos foram convidados a realizar medições de objetos da sala de aula, usando uma unidade de medida não convencional, distribuída a todos os alunos - uma tira de papel, e a anotar as medidas encontradas. Não permitimos o uso da régua graduada em centímetros, visto que ela possibilita a medição de objetos "pequenos", usando os milímetros, e, desta forma, não se apresenta a necessidade do uso de frações da unidade.

Diversas foram as formas de manipular a tira de papel e as anotações sobre as medidas, conforme pode ser observado na figura 4 e 5 a seguir. 
Figura $4^{2}$ : Alunos na atividade de medição

Figura $4^{3}$ : Alunos na atividade de medição

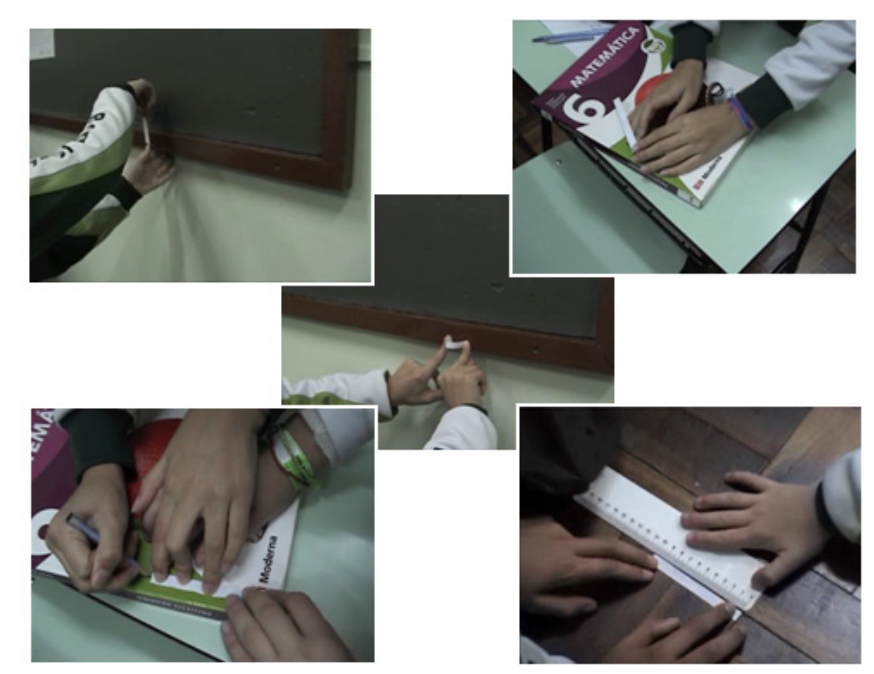

Figura 5: Resultados das medições
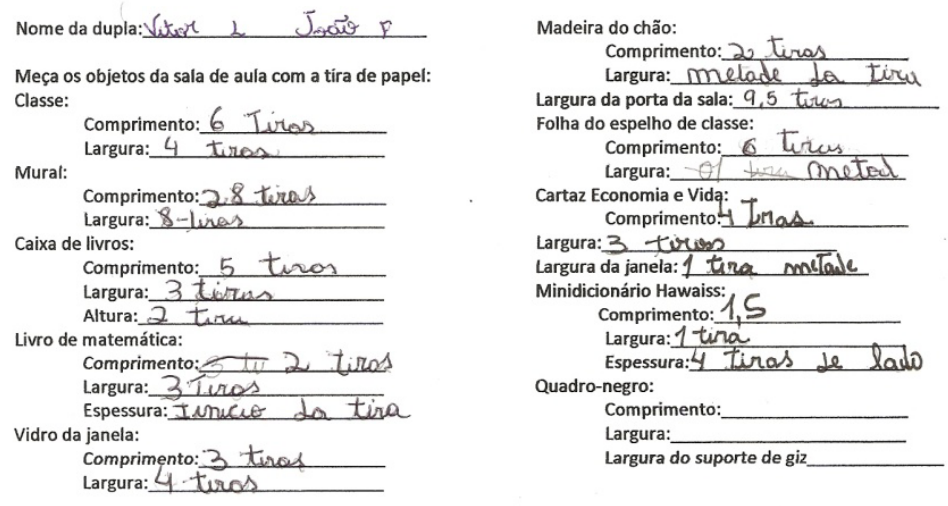

Unindo o que este material nos mostra e mais as falas e atitudes dos alunos identificamos invariantes operatórios na forma de conceitos em ação e teoremas em ação, na qual interpretamos da seguinte forma:

Conceitos em ação: (i) medir é comparar com a unidade escolhida; (ii) medir é saber quantas vezes a unidade escolhida cabe no objeto.

Teoremas em ação: (i) se a unidade vale $10 \mathrm{~cm}$, então $\mathbf{n}$ vezes a unidade vale $\mathbf{n}$ vezes 10 cm (alunos que usaram régua, figura 4); (ii) se sobrar um pouquinho da unidade, então a medida é um número inteiro; se sobrar um tamanho razoável da unidade, então a medida é a metade da unidade; (iii) o valor da medida depende da unidade.

\footnotetext{
${ }^{2}$ O livro didático que aparece nas fotos é Barroso (2007), adotado pela escola.

${ }^{3} \mathrm{O}$ livro didático que aparece nas fotos é Barroso (2007), adotado pela escola.
} 
Concluímos com esta primeira atividade que, na maioria das duplas, a utilização das frações, isto é, da notação $\frac{a}{b}$, não é algo natural, mas o raciocínio que apresentam mostra que estão entendendo a ideia de número fracionário. Ao escrever "a metade" e "início da tira", podemos dizer que o aluno percebe a existência destes números "fracionados", mas não possui conhecimento para expressá-los na notação fracionária.

Com o intuito de proporcionar, para os alunos, a utilização desta notação fracionária para os números "quebrados", elaboramos uma atividade de construção de régua graduada com frações. Neste momento, o número fracionário assume seu significado medida de forma que será um ponto sobre uma reta e representará uma medida.

Os alunos receberam um papel para desenhar sua régua e uma tira de papel, de aproximadamente $10 \mathrm{~cm}$, para utilizarem como unidade de medida. Orientamos quanto à construção e às frações que poderiam ser construídas. Abaixo, extratos de cinco réguas construídas pelos alunos, na qual cada uma possui peculiaridades que as diferenciam ao mesmo tempo que possuem elementos comuns - os invariantes operatórios.

Figura 5: Régua 1

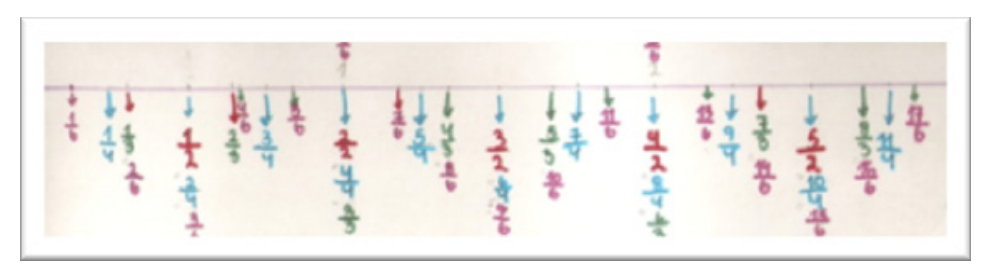

Figura 6: Régua 2

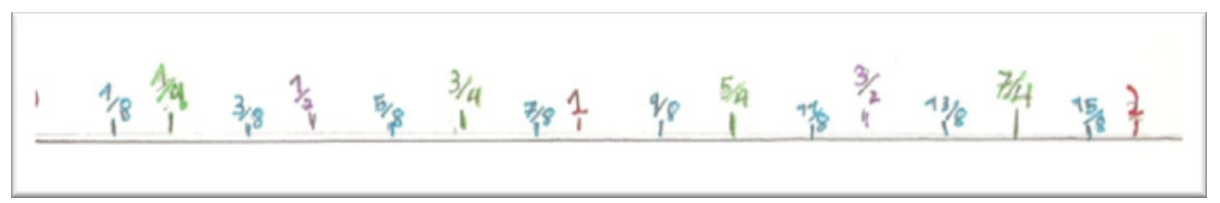

Figura 7: Régua 3

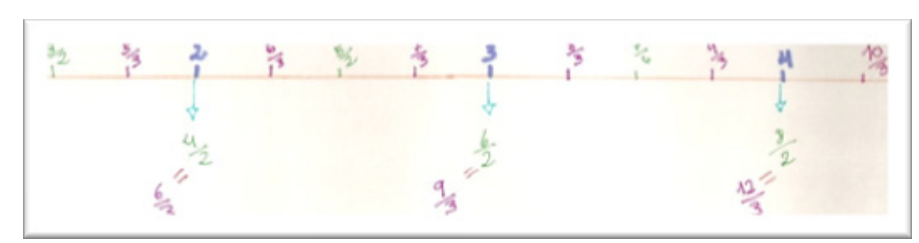


Figura 8: Régua 4

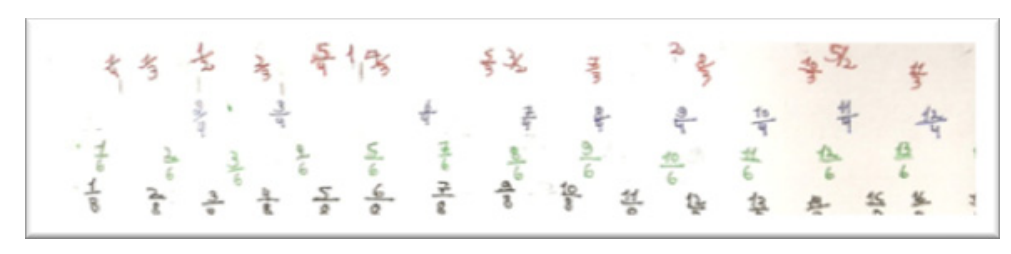

Figura 9: Régua 5

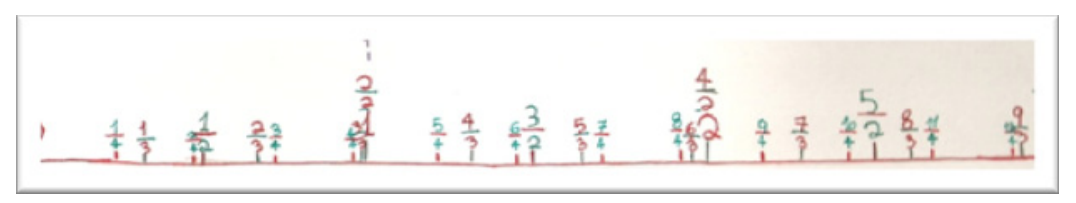

A régua 1 está bem construída, com excelente precisão das medidas. A régua 2 é caracterizada por não apresentar as equivalências, ou pelo menos, de estarem implícitas, assim temos o teorema em ação: se já tem um número associado a ponto da reta, então não há necessidade de associar outro número equivalente.

Na régua 3, percebemos que o aluno "pulou" números inteiros quanto marcava as frações, assim, temos o teorema em ação: os números inteiros não fazem parte da marcação dos números fracionários. Já na régua 4 , percebemos uma marcação diferente, onde, para cada denominador, tem-se um nível e uma cor, e, sendo realizadas as marcações das linhas com certa coerência, porém não há uma correspondência entre as frações de denominadores diferentes.

E, por último, na régua 5 é interessante notar que há coerência nas frações equivalentes marcadas, apesar de não estarem no mesmo ponto. Isso evidencia a falta de precisão das marcações ou talvez a não compreensão das equivalências como diferentes números que representam a mesma medida e que estão no mesmo ponto da régua.

De modo geral, tanto na análise das réguas já construídas como nas observações que realizamos do processo de construção, evidenciamos outro teorema em ação comum a todas elas: para marcar o número fracionário $\frac{m}{n}$, devemos dividir a unidade em $\mathbf{n}$ partes iguais e fazer a contagem destas partes conforme o numerador m deste número. Deste modo, estes conhecimentos em ação identificados nos mostram que os alunos compreenderam a correspondência entre números fracionários e pontos de uma reta. 
A terceira atividade buscou realizar uma sistematização do que foi trabalhado anteriormente, com maior exigência de abstração (no sentido oposto à atividade prática com objetos manipuláveis), já que a régua e o objeto a ser medido estarão desenhados num papel. Para este trabalho, foi organizada uma folha com três exercícios envolvendo réguas numeradas.

No primeiro exercícios identificamos o teorema em ação que se refere ao número misto: se uma medida é maior do que a unidade, então pode ser representada por um múltiplo da unidade mais uma parte fracionária desta unidade; que pode ser observado na figura abaixo.

Figura 10: Atividade resolvida

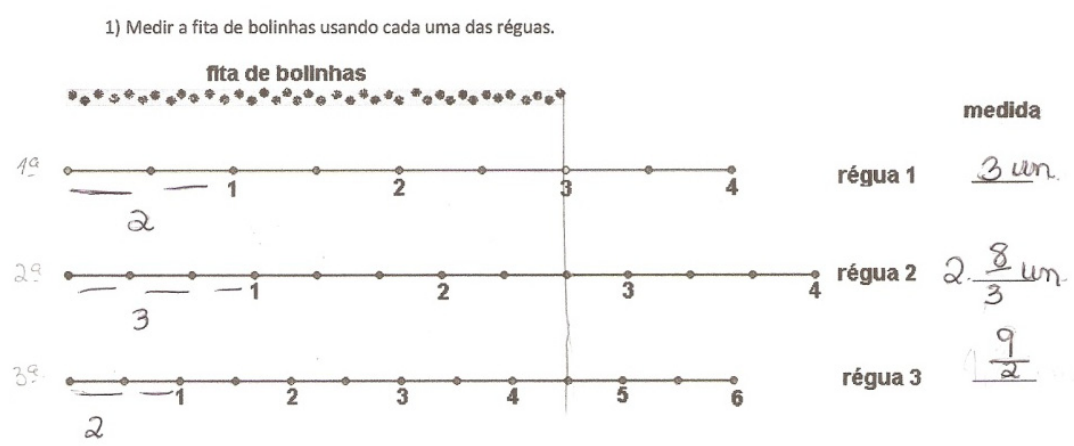

Entre as medições equivocadas dos alunos, vemos ainda partições errôneas da unidade, nas quais contam os pontos e não os segmentos. Por exemplo na figura 11 abaixo, registram como medida o número fracionário $\frac{8}{2}$ na "régua 2 ". Assim, entendemos que o aluno considerou que a unidade está dividida em duas partes, pois "olhou" para os pontos entre a origem " 0 " e o " 1 " e não para os segmentos,. Dessa forma, o correto seria $\frac{8}{3}$.

Figura 11: Atividade resolvida

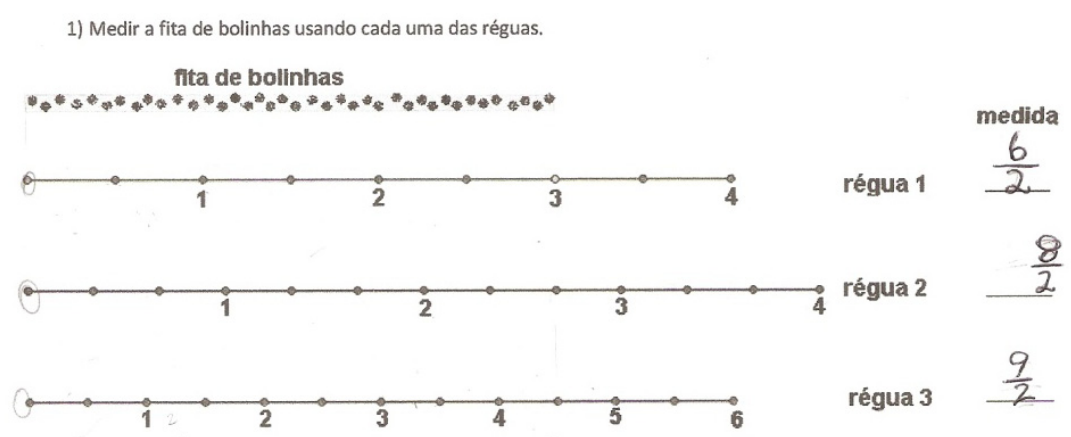

O segundo exercício solicitava a medida (posição) do ponto identificado com uma seta. A passagem do uso da régua numerada (contexto concreto) para a reta numérica (contexto abstrato) causou certa dificuldade. O trabalho que vinha sendo realizado até então utilizava 
réguas para medir objetos e, a partir de agora ela teria outro significado - os números associados a medidas de segmentos da própria reta.

Entre as respostas, podemos destacar um caso em que a marcação do número fracionário está sobre os intervalos entre os pontos e não sobre os pontos, conforme a figura 12. Temos, então, um conceito em ação: os números fracionários estão associados a segmentos, de forma equivocada. Isto por que trata de uma associação entre números e segmentos que é não pertinente, frente a convenção que associa, na reta, números a pontos. Por exemplo, ainda na figura 12 , o aluno associa os número fracionários $\frac{1}{8}, \frac{2}{8}, \frac{3}{8} \ldots$, a uma sequência de segmentos consecutivos. Assim, a noção do que representa $\frac{2}{8}$ talvez ainda não esteja clara. Não há problema em associar números a segmentos desde que seja segmento de tamanho condizente com o número. Assim, o número $\frac{2}{8}$, deveria ser associado ao segmento que vai do zero até o ponto $\frac{2}{8}$, conforme a indicação de vermelho abaixo.

Figura 12: Atividade Resolvida

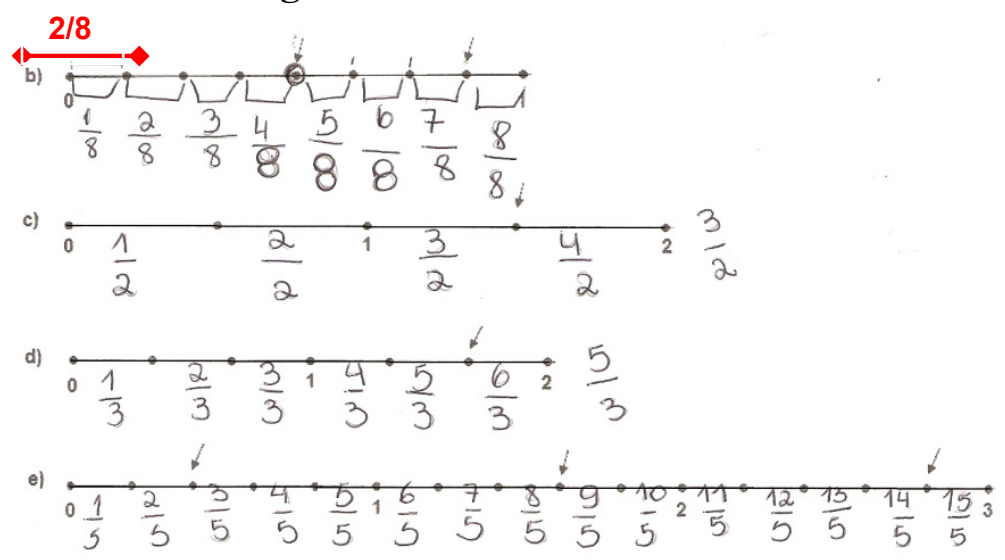

Outro fato observado, na conversa entre os alunos, foi a ideia de que, para identificar o denominador da fração, deve-se considerar os pontos marcados entre o "0" e o " 1 ” e não os segmentos obtidos nestas divisões. Já vimos esta ideia no exercício 1, na figura 11 (régua 2) mostrada anteriormente. Portanto, estes alunos manifestaram um teorema em ação equivocado: se há n pontos entre os extremos da unidade, então a unidade está dividida em n partes. 
Também vemos que, em outros registros, além de fazer as contagens de pontos e não de segmentos, eles contavam também o ponto sobre a origem "0" e sobre o "1", conforme a figura 13.

Figura 13: Atividade resolvida

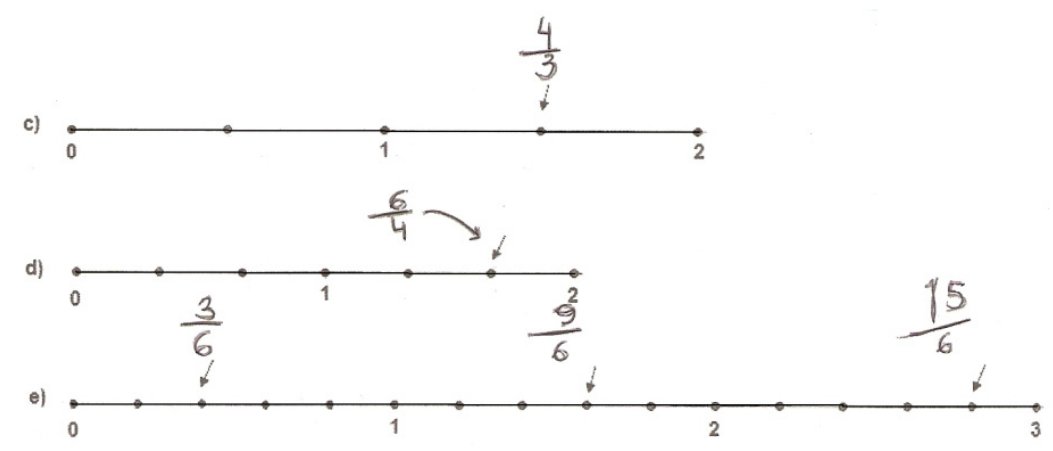

Parece-nos que, na questão (c), da figura 13, o aluno interpretou o número $\frac{4}{3}$ da seguinte forma: o número 3 está associado ao número de pontos destacados no segmento com extremos em zero e um; e o número 4 está associado ao número de pontos destacados no segmento com extremos em zero e naquele destacado pela seta. É com o mesmo raciocínio que ele localiza os demais números fracionários nos outros itens.

Assim, percebemos que a estratégia do aluno possui coerência, porém não está de acordo com a formalização. Aqui temos um teorema-em-ação semelhante ao anterior: se há n pontos sobre a unidade, então a unidade está dividida em n partes e, portanto, o denominador das frações será $n$.

No terceiro e último exercícios desta atividade, observamos diferentes formas de construção das réguas solicitadas. Entre elas, observamos, na figura 14, que, além do cuidado em construir duas réguas, uma para cada número fracionário, ao marcar $\frac{7}{6}$, o aluno não divide a unidade em 6 partes para tomar 7 destas partes. Pressupomos, então, que o aluno tenha estabelecido a relação de equivalência entre o número 1 e $\frac{6}{6}$, e, dessa forma, manifestou um conceito em ação referente à equivalência. 
Figura 14: Atividade Resolvida

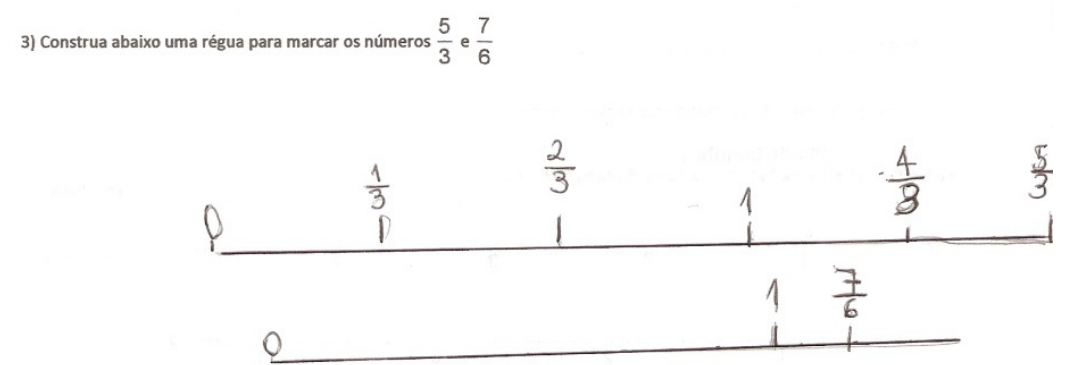

A passagem da régua numerada para a reta numérica não se deu de forma tranquila, pois muitas confusões e equívocos foram cometidos e nossa intervenção com explicações foi necessária. Talvez um dos fatores que contribuiu para as dificuldades foi a forma de representação da reta numérica, a qual propiciou a confusão de pontos com segmentos.

Outras atividades foram realizadas de forma a oportunizar a reformulação de teoremas em ação equivocados que podem ser encontradas em Lessa (2011). Consideramos que erros e equívocos são inerentes ao processo de aprendizagem e constituição de uma nova representação para os alunos, no caso, a reta numérica.

Nosso olhar para as atividades dos alunos, à luz da Teoria dos Campos Conceituais, permitenos enxergar com mais clareza as dificuldades que apresentam e, portanto avaliarmos suas aprendizagens e também as nossas formas de conduzir e planejar as tarefas didáticas. A nossa percepção dos invariantes teorizados por Vergnaud só foi possível após muito estudo e análise da prática para assim, identificá-los como conhecimentos matemáticos válidos ou conhecimentos que precisavam ser reelaborados pelos alunos de modo a se constituírem como válidos no corpo do saber matemático.

Um diálogo mais individualizado com os alunos, a fim de escutar com mais atenção suas falas e interpretar melhor suas atitudes, poderia aprimorar a identificação de outros conceitos e teoremas em ação. Como é de se esperar, diferentes ritmos de aprendizagem se apresentaram no grupo de alunos e mesmo tendo identificado casos de equívocos conceituais ainda no final da experiência, podemos dizer que houve progressos quanto à compreensão do número fracionário no seu significado "medida". E considerando que a aprendizagem é um processo gradual de amadurecimento de ideias, acreditamos que a consolidação do conhecimento relativo a número fracionário também vai depender de recorrente retomada dos seus diferentes significados, em diferentes momentos da educação escolar. 


\section{Referências}

BACKENDORF, V. R. Uma Sequência Didática de Medidas de Comprimento e Superficie no $5^{\circ}$ ano do Ensino Fundamental: um estudo de caso. 2010. 188f. Dissertação (Mestrado em Ensino de Matemática). Instituto de Matemática, UFRGS, Porto Alegre (RS). Disponível em http://www.lume.ufrgs.br/bitstream/handle/10183/25221/000752787.pdf?sequence=1> Acesso em: 16 dez. 2013.

BARROSO, J. M. Projeto Araribá: matemática 6º ano. 2.ed. São Paulo: Moderna, 2007.

LESSA, V. E. A compreensão do conceito de número fracionário: uma sequencia didática para o significado medida. 2011. 167f. Dissertação (Mestrado em Ensino de Matemática). Instituto de Matemática, UFRS, Porto Alegre (RS). Disponível em < http://www.lume.ufrgs.br/bitstream/handle/10183/29355/000776001.pdf?...1 > Acesso em: 18 dez. 2013.

MOREIRA, A. M. A Teoria dos Campos Conceituais de Vergnaud: o Ensino de ciências e a pesquisa na área. Investigação em Ensino de Ciências, v.7(1), p.7-29 Porto Alegre: UFRGS, 2002.

MUNIZ, C. O Conceito de "esquema" para um novo olhar para a produção matemática na escola: as contribuições da Teoria dos Campos Conceituais. In: BITTAR, M.; MUNIZ, C. A aprendizagem matemática na perspectiva da Teoria dos Campos Conceituais. 1.ed. Curitiba: Editora CRV, 2009. p.37-52

VERGNAUD, G. A Trama dos Campos Conceituais na Construção do Conhecimento. Revista do GEEMPA, Porto Alegre, n. 4, Jul. 1996a.

A Teoria dos Campos Conceituais. In: BRUN, J. (org). Didáctica das matemáticas. Lisboa: Instituto Piaget, p.155-91, $1996 \mathrm{~b}$.

A Gênese dos Campos Conceituais. In: GROSSI, E .P.(org.) Por que ainda há quem não aprende? A Teoria. Petrópolis, RJ: Editora Vozes, 2003, p.21-60.

O que é aprender In: BITTAR, M; MUNIZ, C. A. (orgs.). A aprendizagem Matemática na perspectiva da Teoria dos Campos Conceituais. Curitiba: Editora CRV, 2009. 